\section{A new approach to neural drugs}

Eli Lilly and Company would like the summer of 1996 to be remembered as the time when diseases of the brain met their pharmaceutical match. Lilly has about 15 compounds either under development or in clinical trials for a wide range of central nervous system (CNS) diseases, including schizophrenia, depression, Alzheimer's disease, affective (mood) disorders, pain, migraine, smoking cessation, Parkinson's disease, and stroke. "This is perhaps the most exciting time to be discovering and developing drugs, particularly for CNS disorders," says Steven M. Paul, vice president in charge of CNS discovery research and clinical investigation at Lilly.

The reason for this newfound optimism is the coming together of advances both in basic research and in the processes involved in drug testing and discovery. New drug discovery normally requires a 10-to12 year course for a single agent, and is projected to cost US\$1 billion per compound by the next century. Thus drug companies are placing high priority on streamlining the process.

Lilly's neuroscience initiative is dependent on relatively new "combinatorial chemistry" techniques to synthesize and screen thousands of experimental agents in a few weeks' time. In this mechanized process, batches of individual molecules attached to chemical supports are synthesized, and then these anchored compounds are exposed to a biological target of interest. Molecules that interact favorably with the target are identified and separated for further study.

According to Paul, with such highthroughput robotic screening methods, researchers can screen as many as 150,000 compounds against a given biological target in a few months. Once a "hit" (a possible drug lead) is uncovered, its structural and biological features are evaluated, refined and studied in vivo.

From the other side, after specific neurotransmitters and receptors involved in a particular neurologic disease are identified, this rapid screening process may quickly find agents active for them. In this way, new therapeutic advances may be found in record time. "It is clearly possible to go from a well-defined molecular target (such as a receptor) to achieving early human testing of a drug candidate within two years or even sooner," Paul says. FOR COPYRIGHT REASONS
Other variations of combinatorial chemistry approaches to drug discovery are also being developed. Researchers at the Affymax Research Institute, a subsidiary of Glaxo Wellcome, in Palo Alto, California, have developed a solid-phase labeling method that will not only help researchers track each compound tested, but also simplify the elucidation of the structure of biologically active compounds.

Scientists at The Scripps Research Institute in La Jolla, California, are carrying the process a step further by developing new structural supports for use with a solution-based variation of this technique. "Liquid phase supports ... are much more water-soluble than the traditional solid "bead" supports," says Kim Janda professor of molecular biology and chemistry at Scripps.

Although this mechanism-driven approach to drug discovery has fueled much of Lilly's neuroscience research efforts, much more remains to be learned about the basic neurotransmitter systems that modulate brain diseases. Along these lines, recent collaborative efforts between Lilly and Athena Neurosciences have yielded the first reliable transgenic animal model of Alzheimer's disease as well. It is hoped that this new mouse model will assist in screening for drugs that may reduce amyloid deposition (believed to cause Alzheimer's), and possibly inhibit the disease process itself.

Dominic De Bellis Mahopac, New York

\section{Medicines makes its rounds}

An impressive traveling exhibit is making the rounds of major US science museums over the next few years, and it is worth a day out of the laboratory or clinic to see it. Medicines: The Inside Story is part history, part science and part trade show, but it is all educational. Given that every day a new medical "breakthrough" is trumpeted in the mass media, Medicines offers a particularly welcome slice of reality about medicine, its strengths and limitations, and the sizable gaps in our current medical knowledge. It also celebrates the fundamental procedures of biomedical science.

"The goal is to educate people about medicine, but also to IMAGE stimulate interest in health sciences, particularly among high UNAVAILABLE schoolers," says Michael R. Harris, Medicines project director. "We want to encourage young people to consider going into health-related fields, particularly research." To that end, the Medicines project plans to distribute thousands of CD-ROMs that contain not only the highlights of the exhibit, but also lesson plans and suggestions for related teaching opportunities.

The obviously expensive exhibit is financially backed almost entirely by pharmaceutical giant Glaxo Wellcome, although the company's attitude toward the project was "hands off," according to Mark Parascandola, a research associate on the project. Both Parascandola and Harris emphasize that Glaxo Wellcome officials were more concerned to have an accurate, fair and interesting portrayal of medicines and how they are discovered than they were to promote any of the company's particular interests.

In addition to the exhibit and teaching components, the project is offering a 30-minute planetarium presentation entitled Innerspace, Medicines: The Inside Story. This presentation explains, via a "guided tour," the inner workings of the human body. "Planetariums are useful for more than star shows," says Harris, who adds that well over a hundred planetariums (of the 1700 or so estimated in the USA) have already expressed an interest in becoming what he calls "science domes;" sites willing to show Inside Story.

Medicines is en route to the North Carolina Museum of History in Raleigh after spending most of the past year at the Fernbank Museum of Natural History in Atlanta, Georgia. After leaving Raleigh at the end of this year, the exhibit will be open in the Museum of Science and Industry in Chicago, Illinois (January to May, 1997), the California Museum of Science and Industry in Los Angeles (July to December, 1997), the Arizona Science Center in Phoenix (February to September, 1998), and in the Maryland Science Center in Baltimore (November 1998 to November 1999). After that it will either move to another temporary place or be donated permanently to a US museum.

F.R.S. 